INCIDENCE AND CAUSES OF ACUTE KIDNEY INJURY IN SICK NEONATE : A STUDY FROM A TERTIARY CARE NEONATAL UNIT

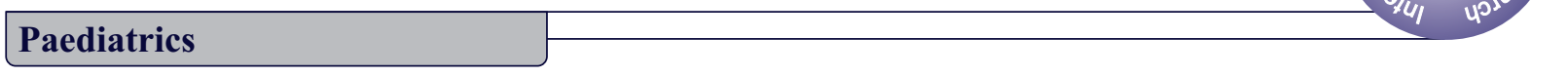

Dr Krishnendu Junior Resident, Department of Paediatric Medicine, Calcutta National Medical College, Karmakar

\title{
Dr. Sumanta
} Kolkata.

Associate Professor, Department of Paediatric Medicine, Calcutta National Medical

Dr. Bhaswati

Ghoshal

College, Kolkata, West Bengal, India. ${ }^{*}$ Corresponding Author

Prof Pradip
Kumar Das

Associate Professor, Department of Paediatric Medicine, Calcutta National Medical

College, Kolkata.

\section{ABSTRACT}

Objective: To find out the incidence of Acute Kidney Injury(AKI) and various causes responsible for the AKI in sick neonates in a tertiary care hospital.

Material And Method: In this observational cross sectional study we included all neonates with features suggestive of AKI with exclusion criteria of extreme prematurity, chronic kidney disease and major congenital anomaly. We diagnose AKI according to the KIDIGO(Kidney Disease: Improving Global Outcome)guideline where we take serum creatinine value and urinary output as determinant. Serum creatinine value measured at 48 and $72 \mathrm{hrs}$ of admission and repeated at $96 \mathrm{hrs}$ if there is rising trend of creatinine..Now we find out the incidence of AKI in relation to gender, birth weight and mode of delivery. Among the AKI case we sort out the causative factors like perinatal asphyxia,sepsis, shock, prematurity etc and analysed all the results statistically.

Results: Out of total 1872 neonates admitted during the 18 months study period we found AKI in 111 neonates(5.93\%).There is male preponderance and most neonates are of normal birth wt.Among the various causes of AKI perinatal asphyxia is the leading cause followed by sepsis and prematurity.Other imp causes are congenital heart disease,shock, PPHN, nephrotoxic drug use and RDS of newborn. We found asphyxia as the leading cause of AKI in normal vaginal delivary group whereas sepsis is the main cause of AKI in cesarean section group.

Conclusion: AKI is fairly common in sick neonates, even in normal birth weight babies and perinatal asphyxia and sepsis are the two most prevalent cause for AKI in this study.

\section{KEYWORDS}

Acute Kidney Injury(AKI), Neonate , Asphyxia, Sepsis,

\section{INTRODUCTION}

Acute Kidney Injury(AKI) is a major contributor of neonatal morbitity and mortality.It has been shown convincingly by the growing evidences that the kidney is not just an innocent bystander in different comorbid condition of the neonate like perinatal asphyxia, sepsis, shock, dehydration, or prematurity. But often we ignore the kidney or fail to recognize the early insult on kidney while treating the primary disease.Available data shows variable incidence of AKI in the Neonatal Intensive Care Unit(NICU) around the globe ranging from 6$24 \%{ }^{1}$. The data on AKI from the Indian subcontinent is very limited. More importantly there are several gaps including the use of appropriate definition of AKI, risk factor, demographic profile and association with other co-morbidities. Hence we planned a study to find out the incidence of AKI in a tertiary care neonatal unit and also to delineate the different causes of AKI in sick neonates. There is still no definitively accepted definition of neonatal AKI and different studies uses different criteria to define AKI. In our study we have followed the modified KIDIGO (Kidney Disease: Improving Global Outcome) guidelines to define a case having AKI.

\section{MATERIALSAND METHOD}

This observational cross sectional study was conducted in the Sick Newborn Care Unit (SNCU)of a tertiary care medical college in Kolkata from January 2018 to June 2019. All admitted newborns during this time period are subjected to full history taking,clinical examination and relavant investigation with special reference to their co-morbid conditions like perinatal asphyxia, sepsis, prematurity, congenital heart disease, dehydration, shock, ,respiratory distress syndrome, urological anomaly etc. Our study included all newborns (both term and preterm) with features suggestive of AKI. Exclusion criteria were : 1 . Newborns with major congenital anomaly, 2. chronic kidney disease and 3. gestatational age less than 28 weeks(extreme preterm). Acute kidney injury in a neonate was diagnosed and classified according to the modified KIDIGO classification criteria for neonates., where we take serum creatinine value and urine output of the baby to diagnose AKI.. Increase in serum creatinine(SCr) of $0.3 \mathrm{mg} / \mathrm{dl}$ or more within $48 \mathrm{hrs}$ or increase in $\mathrm{SCr} 1.5$ times the baseline and urine volume $<0.5 \mathrm{ml} / \mathrm{kg} / \mathrm{hr}$ for $6-12 \mathrm{hrs}$ indicates AKI.We measured urine output of the baby by using urine collecting adhesive bags at $\mathrm{ml} / \mathrm{kg} / \mathrm{hr}$. To diagnose AKI we measured serum creatinine value at $48 \mathrm{hrs}$ and $72 \mathrm{hrs}$ of admission and repeated at $96 \mathrm{hrs}$ if there is rising trend of creatinine. We also measure serum electrolytes(sodium, potassium, calcium)and urea at $72 \mathrm{hrs}$. If there is any evidence of AKI, blood samples of above parameters are measured twice weekly till the outcome. All newborns diagnosed with AKI are treated conservatively along with intermittent peritoneal dialysis if indicated. We have tried to find out the incidence of AKI among the babies. Various etiologies of AKI have been sorted out. Data was processed by statistical software Statistical version 16.0 . with $p$ value less than 0.05 as significant.

\section{RESULTS}

We found AKI in 111 babies among the total 1872 newborns admitted in our SNCU during the study period.So the total incidence of AKI is $5.93 \%$.Among them $73(65.77 \%)$ neonates of AKI were born by normal vaginal delivery and $38(34.23 \%)$ by cesarean section. $63(56.76 \%)$ babies were inborn and 48(43.24\%)were outborn. Percentage of male $67(60.36 \%)$ is more than female $44(39.64 \%)$.

Total $87(78.38 \%)$ were of normal birth wt, 21(18.92\%) were low birth wt and $3(2.70 \%)$ were very low birth wt (Table 1$)$

Table1. Showing Distribution Of Birth Wt In AKI Cases.

\begin{tabular}{|l|l|l|}
\hline \multicolumn{2}{|l|}{ Total no of AKI cases(N)=111 } & Percentage\% \\
\hline Birth wt(Kg) & No & 78.38 \\
\hline Normal birth wt(2.5 or more) & 87 & 18.92 \\
\hline Low birth wt(1.5-2.49) & 21 & 2.70 \\
\hline Very low birth wt(1-1.49) & 03 & \\
\hline
\end{tabular}

Table 2. Showing Different Causes Of AKI

\begin{tabular}{|l|l|l|}
\hline \multicolumn{3}{|c|}{ Total no of AKI cases(N)=111 } \\
\hline Cause & No & Percentage\% \\
\hline Asphyxia & 53 & 47.75 \\
\hline Sepsis & 33 & 29.74 \\
\hline
\end{tabular}




\begin{tabular}{|l|l|l|}
\hline Prematurity & 12 & 10.81 \\
\hline Congenital Heart Disease & 5 & 4.5 \\
\hline Shock & 3 & 2.7 \\
\hline PPHN & 3 & 2.7 \\
\hline Nephrotoxic drug use & 1 & 0.9 \\
\hline RDS & 1 & 0.9 \\
\hline
\end{tabular}

From Table 2 ,we can see the different causes of AKI,with perinatal asphyxia $53(47.75 \%)$ and sepsis $33(29.74 \%)$ being the major contributory factor of AKI. Other important causes are prematurity 12 ( $10.81 \%)$, congenital heart disease $5(4.5 \%)$,shock $3(2.7 \%)$ and PPHN $3(2.7 \%)$. We got one case of AKI due to nephrotoxic drug use (Amikacin) and one case due to RDS (respiratory distress syndrome) of newborn.

Table 3. Showing Distribution Of Causes Between Different Modes Of Delivary

\begin{tabular}{|l|l|l|l|l|}
\hline \multirow{2}{*}{$\begin{array}{l}\text { Causes of } \\
\text { AKI }\end{array}$} & \multicolumn{2}{|l|}{$\begin{array}{l}\text { Total patients(Cesarean } \\
\text { Section)CS=38 }\end{array}$} & $\begin{array}{l}\text { Total patients(Normal } \\
\text { vaginal delivary) } \\
\text { NVD=73 }\end{array}$ \\
\cline { 2 - 5 } & No & $\begin{array}{l}\text { Percentage } \\
\%\end{array}$ & No & $\begin{array}{l}\text { Percentage } \\
\%\end{array}$ \\
\hline Asphyxia & 5 & 13.17 & 48 & 66.66 \\
\hline Sepsis & 19 & 50 & 14 & 18.06 \\
\hline Prematurity & 6 & 15.79 & 6 & 8.33 \\
\hline $\begin{array}{l}\text { Congenital } \\
\text { Heart } \\
\text { Disease }\end{array}$ & 2 & 5.26 & 3 & 4.17 \\
\hline Shock & 2 & 5.26 & 1 & 1.39 \\
\hline PPHN & 2 & 5.26 & 1 & 1.39 \\
\hline $\begin{array}{l}\text { Nephrotoxic } \\
\text { drug use }\end{array}$ & 1 & 2.63 & 0 & 0 \\
\hline RDS & 1 & 2.63 & 0 & 0 \\
\hline
\end{tabular}

In Table 3, we can see the comparison of different causes of AKI in NVD and CS group.Here asphyxia is the leading cause of AKI in NVD group $(66.66 \%)$ in comparison to CS group $(13.17 \%)$.Sepsis is the main cause of AKI in CS group $(50 \%$ ), whereas it is $18.06 \%$ in NVD group.We found same no of cases(6) of prematurity in both groups, though percentage differs. Congenital heart disease, 2 and 3 cases in CS and NVD group respectively. No of cases of AKI due to shock and PPHN are 2 each in CS group and 1 each in NVD group.We found 1 case of AKI due to nephrotoxic drug use(Amikacin)and 1 case due to RDS in CS group, whereas it is nil in NVD group.

\section{DISCUSSION}

In our study out of total 1872 admitted newborns in SNCU, $111(5.93 \%)$ babies were diagnosed as having AKI. A previous study from India found the incidence of AKI in newborn to be 3.9 per 1000 live births and 34.5 in 1000 newborns admitted in the NICU. ${ }^{2}$.In another recent study where serum creatinine was used as only criteria ,incidence of AKI was $6.3 \%$, which is almost nearer to our result. ${ }^{3}$.Our study shows male preponderance of AKI $60.36 \%$ male \& $39.64 \%$ female $)(p=0.029)$ in accordance with other study. ${ }^{4}$,We found AKI more common among inborn $(56.76 \%)$ than outborns $(43.24 \%)$ $(\mathrm{p}=0.154)$. In this study no of AKI patients were higher in neonate delivered by normal vaginal delivary $73(65.77 \%)$ in comparison to those born by cesarean section $38(34.23 \%)$, which is statistically significant $(\mathrm{p}=<0.0010)$.Various studies suggest AKI is common in VLBW/ELBW newborns. ${ }^{5}$ Koralkar et al reported incidence of AKI using modified KIDIGO criteria to be $18 \%$ among 229 VLBW infants. ${ }^{5}$.Vishwanathan $\mathrm{S}$ et al also reported similar findings. ${ }^{6}$.But surprisingly, in our study we have found that incidence of AKI were higher in neonates having normal birth wt(78.38\%). This could be attributed to the fact that a major portion of full term neonate catered in our study were referred for sepsis or asphyxia which also form a high risk group for AKI.Several previous studies have found perinatal asphyxia to be the most common cause of AKI in neonates as it causes acute tubular injury leading to intrinsic AKI. ${ }^{4}$.Selewski DT et al reported an incidence of $38 \%$ of $\mathrm{AKI}^{7}$ and Kaur S et al reported $41.67 \%{ }^{8}$. We also found perinatal asphyxia $(47.75 \%)$ as the leading cause of AKI in our set up. The newborns with sepsis are thought to be predisposed to $\mathrm{AKI}$ as a result of hypotension secondary to sepsis and a direct damaging effect on renal microvasculature. ${ }^{7}$ In our study we have found 33 neonate $(29.74 \%$ ) with AKI having sepsis as a risk factor, which is similar to the findings of a study from India by Mathur $\mathrm{NB}$ et al. ${ }^{9}$.In our study we have found only 12 preterm $(<37 \mathrm{wks})$ neonates were having AKI(10.81\%), although several other studies show that AKI is higher in preterms. This is probably due to less no of preterms were included in the study. A recent study by Momtaz H E et al reported RDS as a third most common association with $\mathrm{AKI}(34.6 \%)$ after sepsis and dehydration. ${ }^{10}$. However in our study we have found only 1 patients with RDS .Shock is an important risk factor for developing AKI and significant predictor of mortality. ${ }^{9}$ We have found only 3 patients with shock which is $2.7 \%$.Asphxyia causing AKI was higher in NVD group in comparison to CS group,whereas sepsis is a more common cause of AKI in CS group than NVD group.(both are statistically significant with $\mathrm{p}$ value less than 0.05 ).

\section{CONCLUSION}

The present study showed that a significant portion of sick neonates suffers from AKI. We found that it is more prevalent in normal birth weight babies and those with perinatal asphyxia and sepsis , although almost all the common causes of newborn admissions in SNCU can contribute to the occurrence of AKI. Hence it is very important to diagnose acute kidney injury early through a suitable guideline so that we can treat it along with the treatment of the primary co-morbid illness of the newborn.

\section{REFERENCES}

Drukker A, Guignard JP.Renal aspects of the term and preterm infant: A selective update.Curr Opinin Pediatr.2002;14(2):175-82.

2. Aggarwal A,Kumar P,Chowdhary G et al.Evaluation of renal functions in asphyxiated newborns.Journal of tropical pediatrics.2005 Oct 1;51(5):295-9.

3. Vachvanichsanong P,McNeil E,Dissaneevate $\mathrm{S}$ et al.Neonatal acute kidney injury in tertiary center in a developing country.Nephrology Dialysis Transplantation.2012 Sep;27(3):973-7.

4. Gupta BD, Sharma P, Bagla J et al.Renal failure in asphyxiated neonates.Indian pediatrics.2005 Sep 1;42(9):928.

5. Koralkar R, Ambalavanan N, Levitan EB et al.Acute kidney injury reduces survival in very low birth weight infants.Pediatric research.2011 Apr;69(4):354

6. Viswanathan S, Manyam B, Azhibekov T. et al.Risk factor associated with acute kidney injury in extremely low birth weight (ELBW) infants.Pediatric Nephrol.2012;27:303-11. Selewski DT, Charlton JR, Jetton JG at al.Neonatal acute kidney injury.Pediatrics.2015 Aug 1:136(2): e463-73

8. Kaur S, Jain S, Saha A et al.Evaluation of glomerular and tubular renal function in neonates with birth asphyxia. Annals of tropical paediatrics. 2011 May 1;31(2):129-34.

Mathur NB,Agarwal HS,Maria A. Acute renal failure in neonatal sepsis. The Indian Journal of Pediatrics.2006 June 1;73(6):499-502

10. Momtaz HE, Sabzehei MK, Rasuli B et al.The main etiologies of acute kidney injury in the newborns hospitalized in the neonatal intensive care unit.J.Clin Neonatol.2014;3 99-102 